Report No. BMI-1380

UC-25 Metallurgy and Ceramics (TID-4500, 15th Ed.)

Navy Department, Bureau of Ships

Contract No. NObs $=65057$

Index No. NS $-200=023$

(Affiliated with Contract No. W -7405 meng $m 92$ )

\title{
HYDROGEN PICKUP DURING CORROSION \\ OF ZIRCONIUM ALLOYS
}

by

\author{
Warren E. Berry \\ Dale A. Vaughan \\ Ear1 L. White
}

September 24, 1959

BATTELLE MEMORIAL INSTITUTE

$505 \mathrm{King}$ Avenue

Columbus 1, Ohio 


\section{DISCLAIMER}

This report was prepared as an account of work sponsored by an agency of the United States Government. Neither the United States Government nor any agency Thereof, nor any of their employees, makes any warranty, express or implied, or assumes any legal liability or responsibility for the accuracy, completeness, or usefulness of any information, apparatus, product, or process disclosed, or represents that its use would not infringe privately owned rights. Reference herein to any specific commercial product, process, or service by trade name, trademark, manufacturer, or otherwise does not necessarily constitute or imply its endorsement, recommendation, or favoring by the United States Government or any agency thereof. The views and opinions of authors expressed herein do not necessarily state or reflect those of the United States Government or any agency thereof. 


\section{DISCLAIMER}

Portions of this document may be illegible in electronic image products. Images are produced from the best available original document. 
TABLE OF CONTENTS

Page

ABSTRACT .

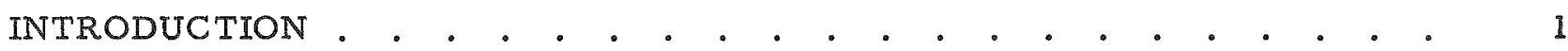

EXPERIMENTAL WORK AND RESULTS • • . • • . . . • . . . . 2

Alloy Additions to Sponge Zirconium . . . . . . . . . . . . 2

Alloy Additions to Zircaloy . . . . . . . . . . . . . . . 5

Effect of Hydride Surface Layers . • . . • . • . . . . . . 8

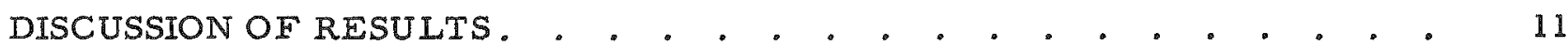

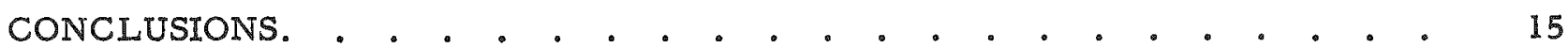

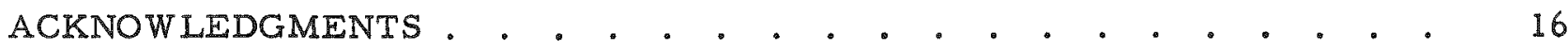

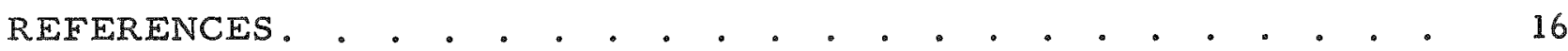




\title{
HYDROGEN PICKUP DURING CORROSION OF ZIRCONIUM ALLOYS
}

\author{
Warren E. Berry, Dale A. Vaughan, and Earl L. White
}

\begin{abstract}
Several factors such as alloy composition, hydrogen content of the alloy, surface hydrides, and hydrogen content of the water have been investigated for their effect upon the amount of hydrogen piched up by zirconium alloys during corrosion in $680 \mathrm{~F}$ water. Metallic additions of nickel increase hydrogen pickup, antimony, chromium, and iron appear to decrease the hydrogen pichup, while the addition of tin has little or no effect. The hydrogen content of the metal (50 to $400 \mathrm{ppm}$ ) or of the water ( 0 to 2 atm of hydrogen pressure) does not appreciably change the amount of hydrogen picked up by the alloys studied. It is proposed that certain intermetallic compounds provide cathodic areas which aid in the concentration of hydrogen at the compound. The amount of corrosion-produced hydrogen entering the metal is controlled by the reaction of hydrogen with the particular compound.
\end{abstract}

The hydriding of Zircaloy-2 by gaseous hydrogen is stopped when small quantities of water vapor are added to the hydrogen.

\section{INTRODUCTION}

During the past 2 years, some fuel-element failures which have been observed in pressurized-water reactors have been attributed to large quantities of hydride observed in the Zircaloy-2 cladding. Descriptions of these incidents have been summarized in WAPD-PWR-PMM-1453.(1) In several of these failures, the amount of hydrogen absorbed exceeded that which was generated from nearby corrosion of the core material or of Zircaloy.

An explanation given by Bettis appeared to correlate these results. This explanation is given in the Bettis report and will not be repeated here.

However, there appeared to be alternative explanations for the Bettis results, and in view of the importance of the subject, it seemed desirable that these be studied briefly. These alternative explanations included the following:

(1) The oxide film over zirconium hydride might be permeable to molecular hydrogen so that hydrogen dissolved in the water might be absorbed.

(2) Nickel might be present as metallic nickel in the oxide film over zirconium-nickel alloys, and be capable of catalyzing the dissociation of molecular to atomic hydrogen, permitting solution. Poisons for the catalysis might then have an effect on hydrogen pickup.

(1) References are at end of report. 
A program was undertaken at Battelle to investigate several of the variables which might influence hydrogen pickup in Zircaloy -2 and zirconium alloys, if these mechanisms were operable. The effect of alloying additions was studied since one of the observed failures occurred where electroplated nickel had diffused into Zircaloy-2 during pressure bonding at elevated temperatures. This portion of the program consisted of examining for hydrogen absorption a sexies of binary alloys from a recently completed corrosion program. The results of this study were then used as a basis for selecting alloy additions to evaluate hydrogen pickup.

The role of surface hydrides and the hydrogen content of the bulk metal and of the water in promoting hydrogen absorption also was investigated, as was the corrosion resistance of zirconium hydride.

\section{EXPERIMENTAL WORK AND RESULTS}

\section{Alloy Additions to Sponge Zirconium}

The effect of alloying additions on hydrogen pickup was studied on a binary-alloy series of sponge-base zirconium containing chromium, iron, nickel, and tin which had been exposed in static 680 F degassed water for times ranging up to 575 days.

Zircaloy -2 and an antimony alloy series also were investigated. All specimens had been exposed well beyond the transition in corrosion rates and exhibited total weight gains of approximately $125 \mathrm{mg}$ pex $\mathrm{dm}^{2}$. The corrosion films appeared to be adherent on all specimens. Only on a $1.8 \mathrm{w} / 0$ nickel alloy was there an indication of any specimen losing weight. All specimens had been analyzed for the major alloy addition while a complete analysis was obtained on the starting sponge zirconium. Hydrogen analyses before corrosion testing had not been secured for the alloys, but were presumed to be about equal to the 20 -ppm content of the sponge base.

The weight gains and hydrogen pickup after corrosion testing are presented in Table 1 for the alloy series. The corrosion results indicate that the binary alloys containing up to $0.85 \mathrm{w} / 0$ nickel were the most corrosion resistant, followed in order by Zircaloy -2 , the iron and the antimony alloys. The chromium and tin alloys were less resistant than the base.

The amount of hydrogen pickup compared with that liberated during corrosion also is shown in Table 1. Assuming that all of the hydrogen pickup by an individual specimen is a result of corrosion of that particular specimen, it is quite apparent that the nickel alloys absorb a higher percentage of corrosion hydrogen than the other alloys and that zirconium sponge and Zircaloy -2 absorb as much as 50 per cent of the theoretical hydrogen.

The per cent theoretical hydrogen versus alloy content is plotted in Figure 1. It can be seen that even the $0.06 \mathrm{w} / 0$ nickel alloy absorbs approximately 75 per cent of the hydrogen from corrosion. The tin alloys behave much like the sponge zirconium, while antimony, chromium, and iron alloys exhibit a minimum in theoretical hydrogen pickup at very low alloy levels. 
TABLE 1. SPONGE-BASE ZIRCONIUM ALLOYS EXPOSED IN STATIC 680 F WATER

\begin{tabular}{|c|c|c|c|c|c|}
\hline \multirow[b]{2}{*}{$\begin{array}{c}\text { Alloy Addition, } \\
\text { w/o }\end{array}$} & \multirow[b]{2}{*}{$\begin{array}{c}\text { Exposure Time, } \\
\text { days }\end{array}$} & \multirow[b]{2}{*}{$\begin{array}{c}\text { Total Weight Gain, } \\
\text { mg per dm }\end{array}$} & \multicolumn{3}{|c|}{ Hydrogen Absorbed } \\
\hline & & & PPM & $\mathrm{Mg}$ per $\mathrm{Dm}^{2}$ & $\begin{array}{l}\text { Per Cent of } \\
\text { Theoretical }\end{array}$ \\
\hline Unalloyed(a) & 168 & 146 & 215 & 8.6 & 46 \\
\hline Zircaloy -2 & 406 & 112 & 107 & 8.1 & 58 \\
\hline $0.29 \mathrm{Sn}$ & 126 & 118 & 177 & 6.7 & 45 \\
\hline $0.51 \mathrm{Sn}$ & 112 & 147 & 189 & 8.4 & 45 \\
\hline $0.16 \mathrm{Fe}$ & 532 & 118 & 128 & 5.9 & 39 \\
\hline $0.24 \mathrm{Fe}$ & 392 & 113 & 77 & 3.5 & 24 \\
\hline $0.50 \mathrm{Fe}$ & 392 & 117 & 114 & 4.3 & 29 \\
\hline $1.07 \mathrm{Fe}$ & 392 & 127 & 180 & 7.9 & 49 \\
\hline $0.05 \mathrm{Cr}$ & 126 & 134 & 60 & 2.5 & 15 \\
\hline $0.24 \mathrm{Cr}$ & 112 & 111 & 80 & 3.8 & 27 \\
\hline $0.55 \mathrm{Cr}$ & 70 & 153 & 96 & 3.9 & 20 \\
\hline $1.30 \mathrm{Cr}$ & 168 & 136 & 130 & 5.8 & 34 \\
\hline $0.06 \mathrm{Ni}$ & 574 & 113 & 276 & 11.1 & 79 \\
\hline $0.25 \mathrm{Ni}$ & 574 & 139 & 319 & 14.3 & 81 \\
\hline $0.41 \mathrm{Ni}$ & 574 & 109 & 322 & 11.8 & 85 \\
\hline $0.85 \mathrm{Ni}$ & 518 & 118 & 350 & 13.9 & 94 \\
\hline $1.8 \mathrm{Ni}$ & 168 & Lost weight & 550 & 21.5 & $-\infty$ \\
\hline $0.03 \mathrm{Sb}$ & 308 & 112 & 50 & 3.6 & 26 \\
\hline $0.10 \mathrm{Sb}$ & 364 & 107 & 29 & 2.1 & 15 \\
\hline $0.17 \mathrm{Sb}$ & 210 & 145 & 25 & 1.4 & 8 \\
\hline $1.57 \mathrm{Sb}$ & 364 & 118 & 45 & 2.3 & 15 \\
\hline
\end{tabular}

(a) Base alloy contained $0.100 \mathrm{w} / \mathrm{o}$ oxygen, $0.045 \mathrm{~W} / \mathrm{o}$ iron, $0.006 \mathrm{~W} / \mathrm{o}$ nitrogen, $0.005 \mathrm{~W} / \mathrm{o}$ nickel, $0.005 \mathrm{w} / \mathrm{o} \mathrm{tin,} 0.004 \mathrm{w} / \mathrm{o}$ chromium, and $0.002 \mathrm{w} / \mathrm{o} \mathrm{hydrogen}$. 


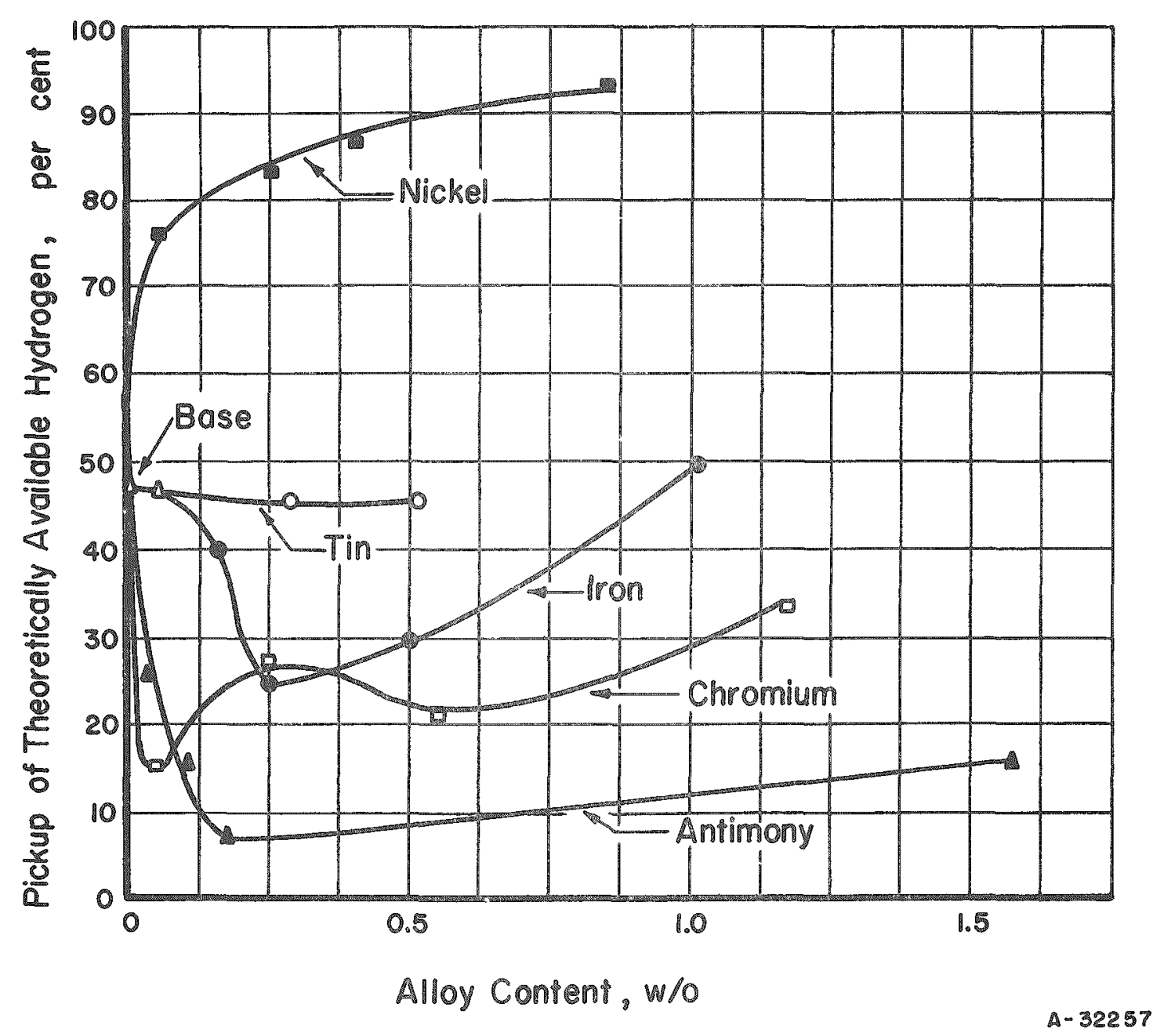

FIGURE 1. SPONGE-BASE ZIRCONIUM ALLOYS EXPOSED UP TO 575 DAYS IN STATIC 680 F WATER 
Examples of the microstructures of the corrosion-tested alloys are shown in Figure 2. The microstructures of the sponge-base and the chromium and low-antimony alloys are similar to those of the tin alloys. The darker hydride needles appear to be uniformly dispersed throughout the specimens and, in most instances, are located at grain boundaries. All of the alloys studied except the tin alloys exhibited increasing compound formation with increasing alloy content, and the compound particles tended to form along grain boundaries. Thus, it appeared that there might be a relationship between the compounds and hydriding susceptibility.

\section{Alloy Additions to Zircaloy}

The high hydrogen pickup by nickel alloys suggested the possibility that nickel was acting as a catalyst to promote hydrogen absorption in zirconium. Traces of antimony and similar elements, such as bismuth, selenium, sulfur, and tellurium are well known for their ability to poison the catalytic effects of nickel. Since it has been demonstrated that antimony additions retard hydrogen absorption in sponge zirconium, it seemed possible that it might have a similar inhibiting effect in Zircaloy-2 which contains nicke1, in addition to other alloying elements.

Experiments were conducted to test the above line of reasoning. They consisted of comparing the behavior of Zircaloy -2 , Zircaloy -2 containing $0.5 \mathrm{w} / 0$ nickel, and the latter alloy containing also an addition of $1 \mathrm{w} / 0$ antimony. Two additional Zircaloy -2 heats, prepared by Bettis for their hydrogen-zirconium studies, were included in this series. These Zircaloy -2 heats contained no nickel additions. In one heat, an equivalent weight of iron was added to replace the nickel while nothing was added to replace the nickel in the second heat.

Corrosion studies were conducted in $680 \mathrm{~F}$ water under (1) low hydrogen pressure and (2) 2 atm of hydrogen to study whether molecular hydrogen in the water affected hydrogen pickup. Palladium valves were employed to control the hydrogen content. Valves on low-pressure units were connected to vacuum pumps while those on the higher pressure units were connected to tank hydrogen through a reducing valve. An additional variable studied was the effect of initial hydrogen content of the metal on subsequent hydrogen absoxption during corrosion. One set of specimens was degassed at $1000 \mathrm{C}$, while a second set was reacted with molecular hydrogen at $600 \mathrm{C}$ and then homogenized at $1000 \mathrm{C}$ to give an initial hydrogen content of approximately $400 \mathrm{ppm}$.

The corrosion results after 107 days' exposure are presented in Table 2. The weight gains of normal Zircaloy -2 and the nickel-free Zircaloy-2 alloys were low, while those of the Zircaloy $-2-0.5 \mathrm{w} / 0$ nickel alloys were high. The weight changes in high-hydrogen water appeared to be lower than those in degassed water.

Postcorrosion hydrogen analyses of the alloys containing 400 ppm of hydrogen were erratic. In a number of specimens, the amount of hydrogen in the alloys after corrosion was less than the initial hydrogen content. It is suspected that the gaseous hydriding process did not result in a uniform hydrogen distribution in the se alloys, and not that hydrogen was lost during corrosion testing. Hydrogen pickup in degassed Zircaloy was lowest in the nickel-frce alloys containing $0.2 \mathrm{w} / 0$ iron, and increased with increasing nickel content. Contrary to expectations, the $1 \mathrm{w} / \mathrm{o}$ antimony addition. did not retard hydrogen pickup in $Z$ ir caloy -2 containing $0.57 \mathrm{w} / 0$ nickel. 


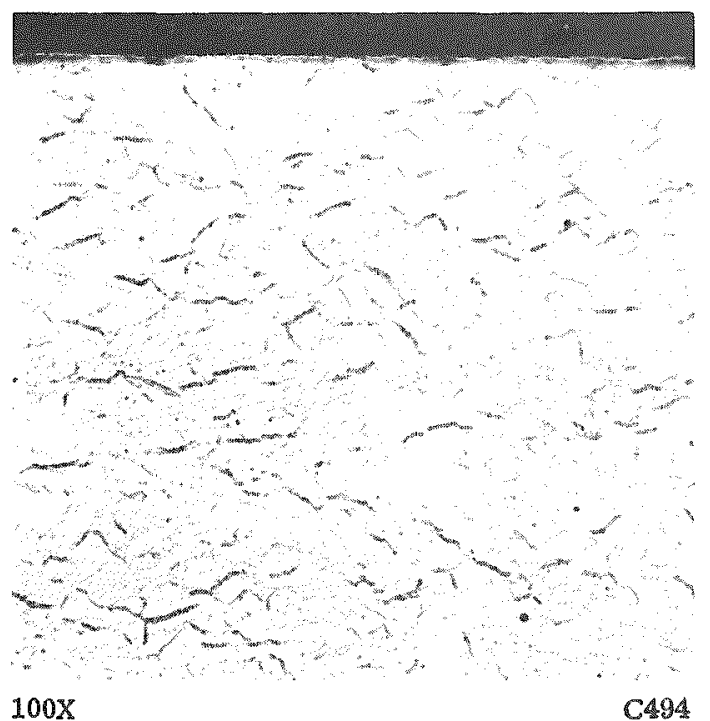

a. Zircaloy-2 After 406 Days ${ }^{\circ}$ Exposure

Hydrogen pickup was 127 ppm.

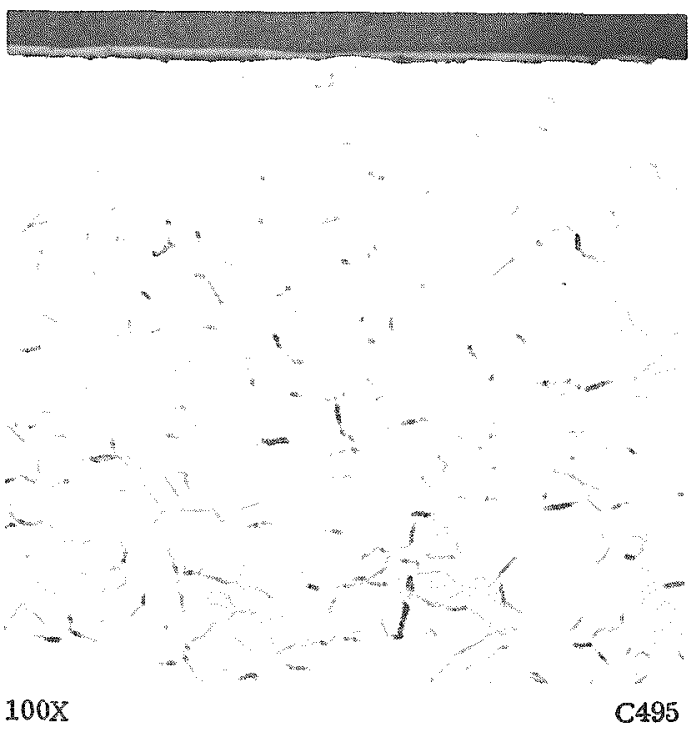

b. $0.29 \mathrm{w} / \mathrm{o}$ Tin After 126 Days' Exposure

Hydrogen puchup was $197 \mathrm{ppm}$.

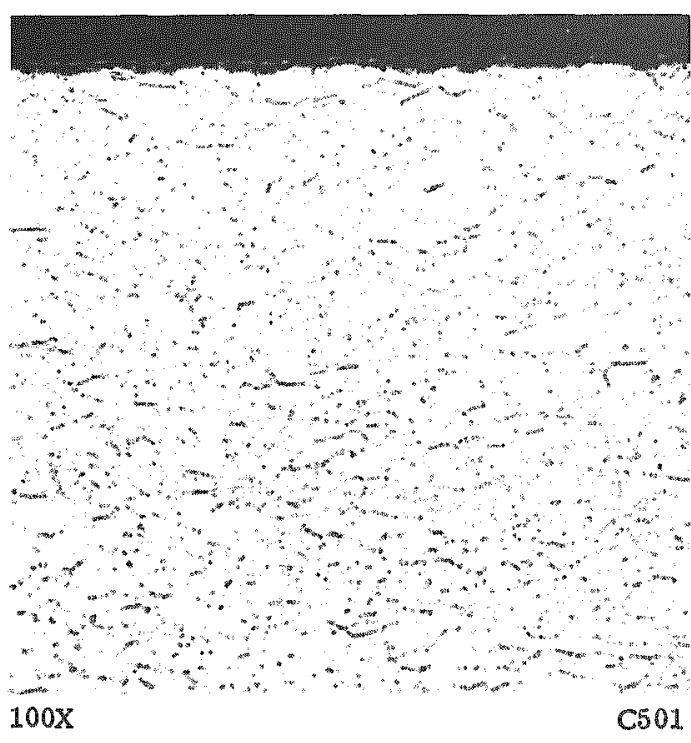

c. 0.50 W/o Iron After 392 Days" Exposure

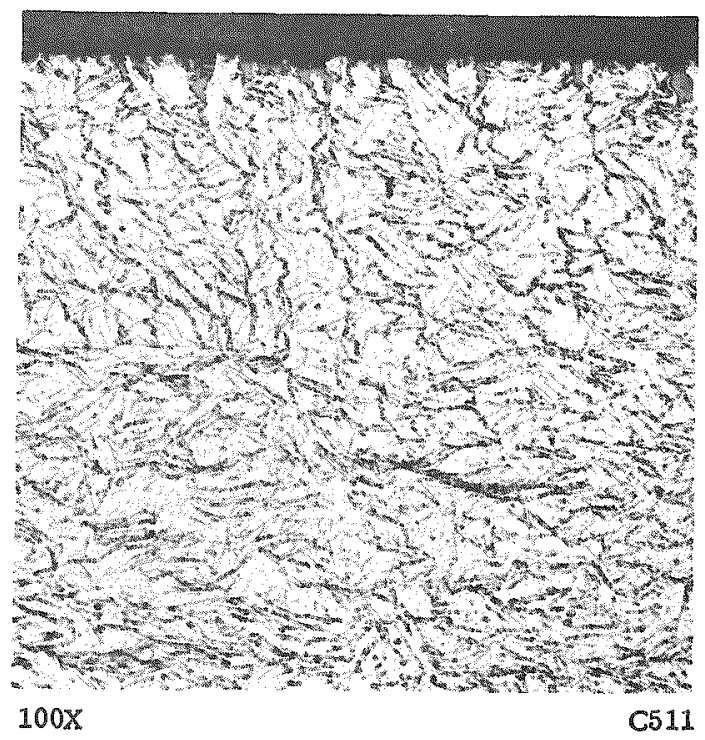

d. 1.8 W/o Nickel After 168 Days ${ }^{\circ}$ Exposure

Hydrogen pickup was 134 ppr.

Hydrogen picliup was 570 ppm.

FIGURE 2. APPEARANCE OF HYDRIDES IN SPONGE-BASE ZIRCONIUM ALLOYS EXPOSED IN STATIC 680 F DEGASSED WATER

Etchant: 30 parts lactic acid, 30 parts nitric acid, 1 part hydrofluoric acid. 
TABLE 2. HYDROGEN PICKUP IN ZIRCONIUM ALLOYS EXPOSED 107 DAYS IN STATIC 680 F WATER

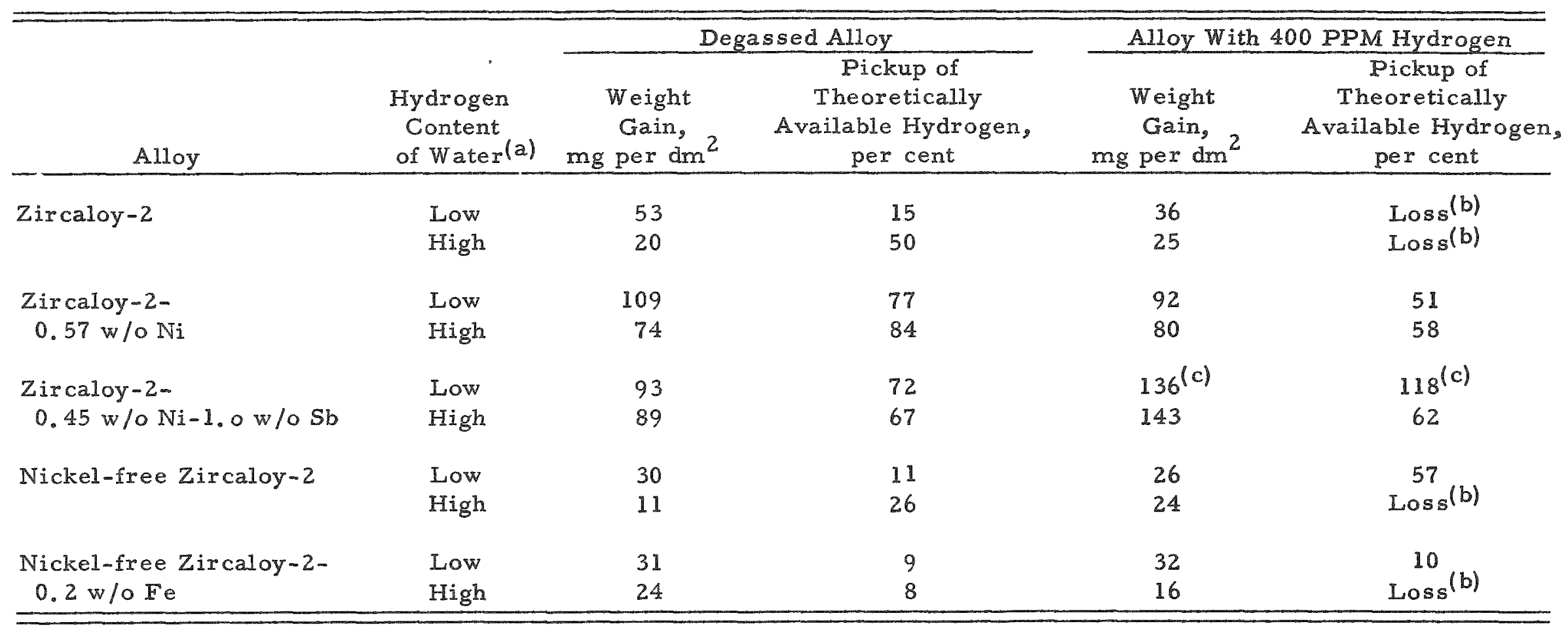

(a) Low hydrogen, degassed; high hydrogen, 2 atm.

(b) Possible variations in hydrogen content within starting material.

(c) Possible loss of corrosion product. 
Hydrogen analyses also were obtained for replicate alloys exposed 14 days in $680 \mathrm{~F}$ water. These data plus those after 107 days' exposure for the degassed alloys are plotted in Figure 3 as a function of total corrosion. A linear relationship is found between hydrogen pickup and total corrosion. As anticipated, the slopes of these lines are not equal for the several alloys and increase with increasing nickel content. The slopes are ratios of the hydrogen pickup to total corrosion and can be converted to theoretical percentages by dividing by 0.125 ( weight of two hydrogen atoms $)$ and multiplying by 100 . In the Zircaloy- 2 specimens the hydrogen pickup doubles with a fifteenfold increase in nickel content. (The nickel-free material contained $0.002 \mathrm{w} / 0$ nickel, the normal Zircaloy -2 contained $0.03 \mathrm{w} / \mathrm{o}$, while the high-nickel alloy contained $0.57 \mathrm{w} / \mathrm{o}$. The slopes of the curves from Figure 3 for these alloys were $0.02,0.04$, and 0.088 , respectively.)

\section{Effect of Hydride Surface Layers}

The effect of a prehydrided surface on hydrogen pickup during corrosion was studied with the Zircaloy -2 and Zircaloy $-2-0.57 \mathrm{w} / 0$ nickel alloys from the alloy program. Specimens were cathodically charged in dilute sulfuric acid to produce a surface hydride layer. One-half of each specimen was then heated 14 days in evacuated capsules at $680 \mathrm{~F}$ to simulate the heat-treated condition of a surface hydride on a corroding sample. As-fabricated alloy specimens with and without the 14-day $680 \mathrm{~F}$ heat treatment were included in the tests for reference purposes.

Results after 25 days $^{\prime}$ exposure in static $680 \mathrm{~F}$ water with 2 atm of hydrogen are shown in Table 3. The hydrided high-nickel specimens corroded at higher rates than the as-fabricated ones. The fraction of hydrogen produced in corrosion that is picked up by the samples varied considerably in the normal Zircaloy-2, but there were no definite indications that a surface hydride layer affected hydrogen absorption during corrosion.

Another type of experiment was made to determine whether the oxide film on Zircaloy was permeable to molecular hydrogen. This was done by establishing the conditions for hydriding Zircaloy in pure hydrogen, then introducing small quantities of water vapor to determine whether or not hydriding stopped completely.

In the first experiment Zircaloy -2 was initially reacted with hydrogen at 662 F and then water vapor was introduced into the static system. A marked change in the reaction rate was observed, but it was not possible to be sure that hydriding stopped completely. Therefore, a dynamic system was constructed in which the inlet-gas mixture was held constant at a flow rate of 1.0 to $1.5 \mathrm{~cm}^{3}$ per min (STP) for a second test, The specimen $\left(0.752 \mathrm{~g}, 1.43 \mathrm{~cm}^{2}\right)$ of Zircaloy-2 was suspended by a fine platinum wire from the beam of a Sartorius vacuum microbalance. The system was evacuated and the specimen heated to $1472 \mathrm{~F}$ for $1 \mathrm{hr}$ to clean the surface and then it was cooled to $662 \mathrm{~F}$. Hydride was produced on the specimen at the lower temperature in flowing dry hydrogen at $76 \mathrm{~mm}$ of mercury pressure. Water vapor was then added to the hydrogen and the reaction extended for $1205 \mathrm{hr}$. The reaction rates obtained in the second tests for the hydrogen and the hydrogen plus water atmospheres are given in Table 4. Again the reaction rate decreased markedly when water vapor was introduced into the hydrogen 


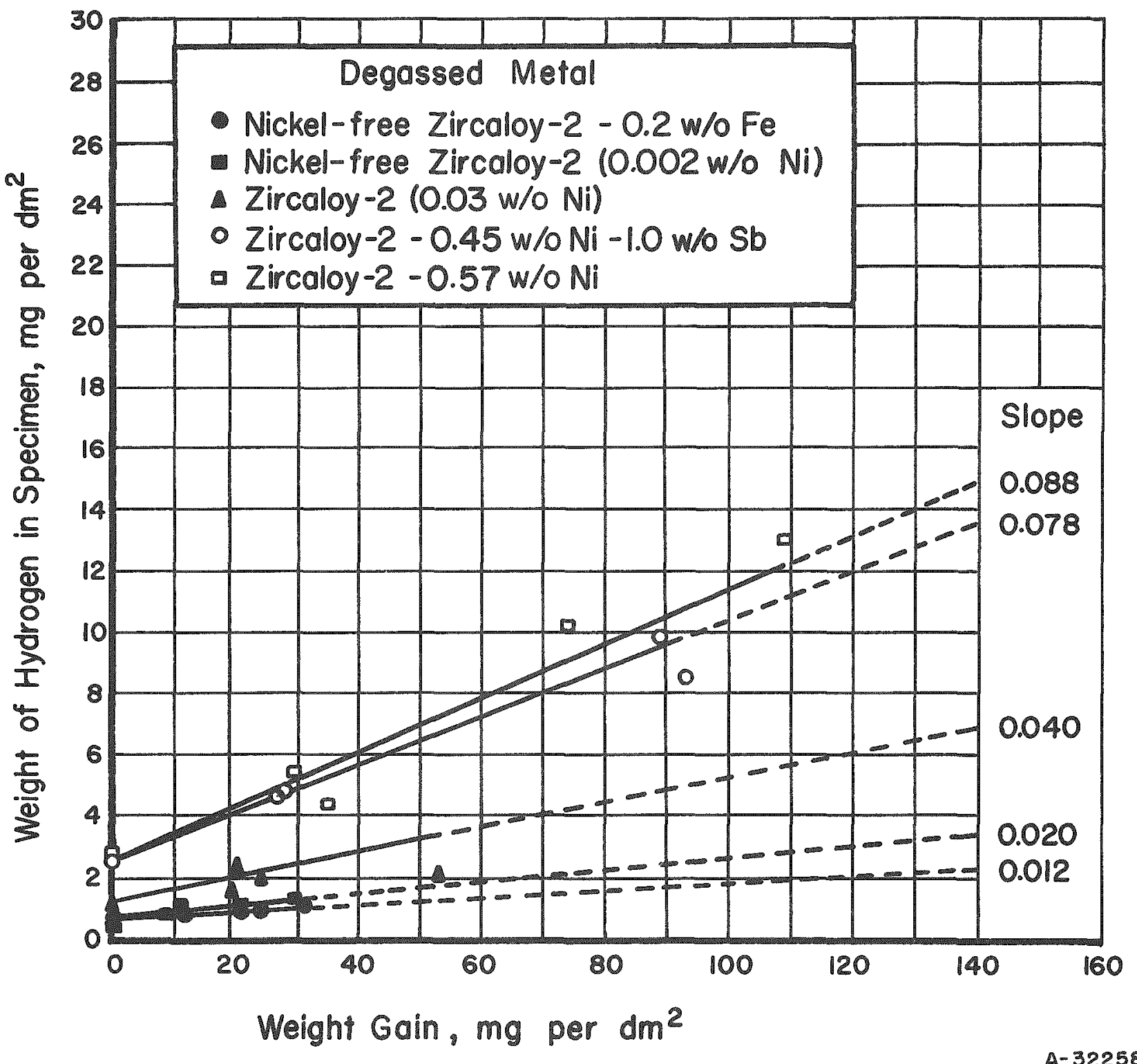

FIGURE 3. MODIFIED ZIRCALOY -2 EXPOSED UP TO 107 DAYS IN STATIC DEGASSED AND HYDROGENATED 680 F WATER 
TABLE 3. ZIRCALOY-2 EXPOSED 25 DAXS IN STATIC 680 F WATER (2 ATM OF HYDROGEN)

\begin{tabular}{|c|c|c|c|c|}
\hline \multirow[b]{2}{*}{ Alloy } & \multirow[b]{2}{*}{ Condition } & \multirow[b]{2}{*}{$\begin{array}{l}\text { Weight Gain, } \\
\text { mg per dm2 }\end{array}$} & \multicolumn{2}{|c|}{ Hydorgen Absorption } \\
\hline & & & $\mathrm{Mg}$ per $\mathrm{Dm}^{2}$ & $\begin{array}{l}\text { Per Cent of } \\
\text { Theoretical }\end{array}$ \\
\hline \multirow[t]{5}{*}{ Zircaloy-2 } & As fabricated & 23 & 0.51 & 18 \\
\hline & 14 days at $680 F$ in vacuum & 21 & 0.12 & 5 \\
\hline & As hydrided & 29 & 0.90 & 25 \\
\hline & Hydrided plus 14 days at & & & \\
\hline & $680 \mathrm{~F}$ in vacuum & 28 & -0.45 & -- \\
\hline \multicolumn{5}{|l|}{ Zircaloy-2- } \\
\hline \multirow[t]{4}{*}{$0.57 \mathrm{w} / 0 \mathrm{Ni}$} & As fabricated & 21 & 2.41 & 80 \\
\hline & 14 days at $680 \mathrm{~F}$ in vacuum & 14 & 2.00 & 114 \\
\hline & As hydrided & 08 & 5.99 & 70 \\
\hline & $\begin{array}{l}\text { Hydrided plus } 14 \text { days at } \\
680 \mathrm{~F} \text { in vacuum }\end{array}$ & 42 & 4.18 & 79 \\
\hline
\end{tabular}

TABLE 4. REACTION RATES OF ZIRCALOY-2 IN DRY HYDROGEN AND OF THE HYDRIDED SURFACE IN WET HYDROGIN AT $662 \mathrm{~F}$

\begin{tabular}{|c|c|c|c|}
\hline \multirow[b]{2}{*}{ Surface Condition(a) } & \multicolumn{2}{|c|}{$\begin{array}{c}\text { Gas Pressure, mm of } \\
\text { mercury }\end{array}$} & \multirow{2}{*}{$\begin{array}{l}\text { Rate Constants } \\
\mu \mathrm{g} \mathrm{per} \mathrm{cm}^{2}, \mathrm{~h} \\
\end{array}$} \\
\hline & Hydrogen & Oxygen & \\
\hline Clean Zircaloy -2 & 76 & -- & 4600 \\
\hline Hydrided Zircaloy-2 & 73.3 & 2.7 & $0.14(b)$ \\
\hline
\end{tabular}

(a) The specimen was first hydrided in dry hydrogen for $0.09 \mathrm{hr}$. Water was added after the weight gain indicated that $=500$ ppm of hydrogen had been absorbed. The final analysis showed that 620 ppm had been picked up durng the total run of 1205 hr.

(b) This rate is based upon the linear portion of the curve shown in Figure 5 after the film is no longer protective. 
atmosphere. The initial change in reaction rate is shown by the weight gain-versustime plot in Figure 4. Subsequent reaction was somewhat erratic, as shown by the points in Figure 5, but suggests the growth of a protective film after water vapor is added to the hydrogen. This film eventually breaks down as in the case of Zircaloy-2(2) with a final linear reaction rate of $0.14 \mu \mathrm{g} /\left(\mathrm{cm}^{2}\right)(\mathrm{hr})$.

Essentially, all of the weight gain which occurred after water vapor was added to the atmosphere was a result of oxidation, as shown by the fact that the hydrogen content increased only from 500 to $620 \mathrm{ppm}$ during the second stage of the test. Thus, the total weight gain owing to oxidation was $200 \mu \mathrm{g}$ per $\mathrm{cm}^{2}$. The total amount of oxidation in the dilute steam atmosphere is comparable to that which occurs in water at the same temperature.(2)

Metallographic examination of the above specimen after reacting with hydrogen and then with hydrogen plus water revealed a thick hydride layer coated with a thin oxide layer. Photomicrographs of the surface of the reacted specimen are shown in Figure 6. The oxidation of the hydrided surface is seen to result in a continuous layer. This film appears to have stopped the hydrogen reaction as described above.

The above results and those of previous work reported in BMI-1120(3) on hydrided surfaces indicate that the initial reaction rate between hydride and water is higher than that between $Z$ ircaloy -2 and water. Since this surface effect may be due to lattice strains, the corrosion behavior of zirconium hydride specimens containing 50, 60, and 65 a/o hydrogen was investigated in the present program. The results are presented in Figure 7. All of the specimens were coated with adherent shiny black films after the corrosion test. The initial weight gains for these alloys are high and may be somewhat in error because of small specimen size. However, this high initial rate confirms the previous studies on hydrided surfaces. It is interesting to note, however, that the high initial rate is followed by a very low rate during extended exposure to $680 \mathrm{~F}$ water.

From these studies on hydride and hydrided surfaces it appears that hydride particles produced during coxrosion do not offer a path for molecular hydrogen to enter the base metal, provided a sufficient amount of water vapor is present to form a protective oxide film. Furthermore, the amount of corrosion on hydride does not appear to be excessive and would not be expected to introduce lar ge quantities of atomic hydrogen.

\section{DISCUSSION OF RESULTS}

This study has shown that the oxide film over zirconium hydride appears to be just as protective against the pickup of molecular hydrogen as that over zirconium itself. The study has discounted the suggestion that the catalytic effect of nickel is the cause of the high hydrogen pickup of nickel alloys. No evidence was found which conflicts with the explanations proposed by BAPD fox the high hydrogen pickup in their studies.

However, the results of this study have not defined the mechanism by which hydrogen is absorbed in zirconium during corrosion in high-temperature water. There is considerable evidence, however, that the source of hydrogen is that produced from 


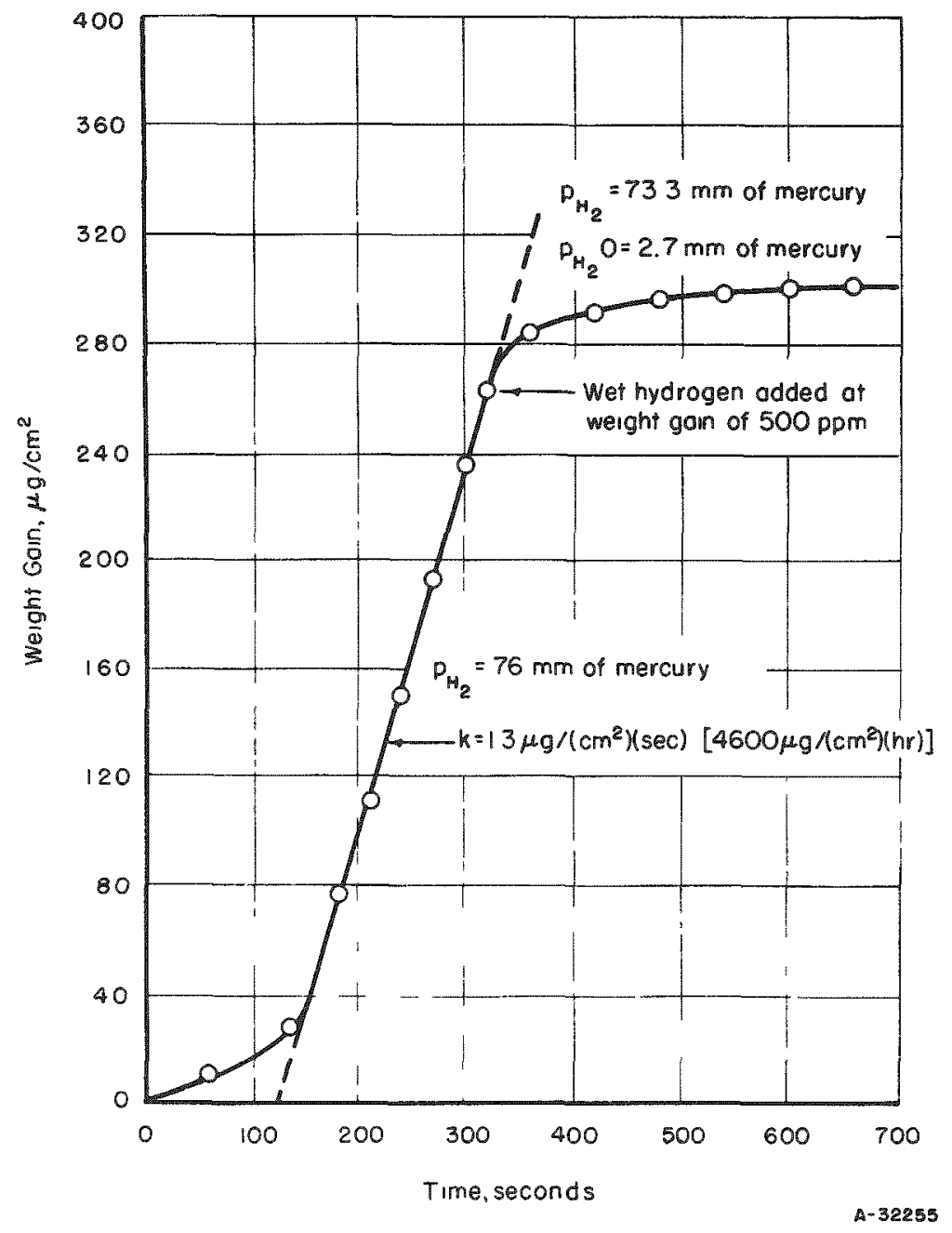

FIGURE 4. INITIAL REACTION OF ZIRCALOY - 2 WITH DRY HYDROGEN FOLLOWED WITH WET HYDROGEN AT $662 \mathrm{~F}$

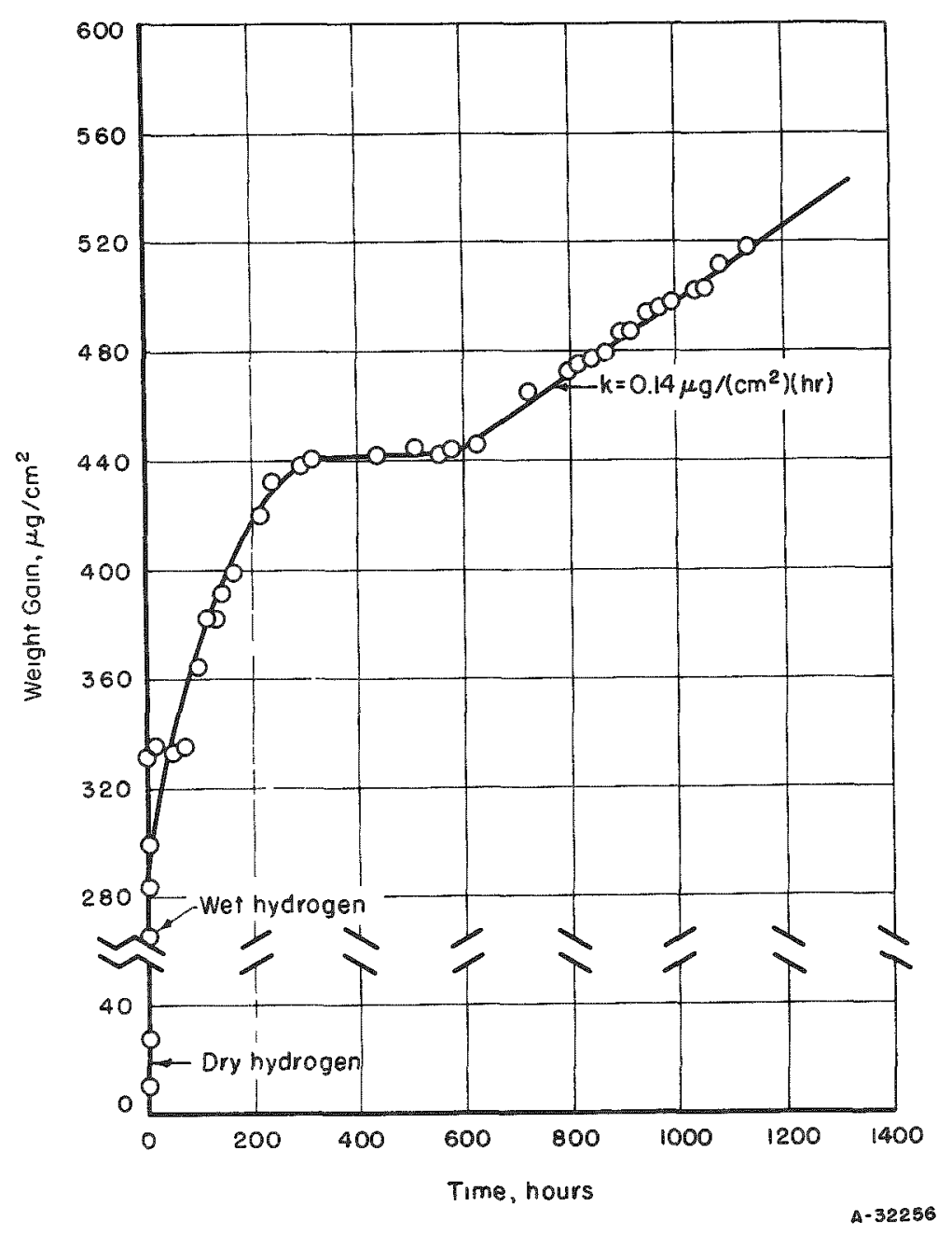

FIGURE 5. LONG-TIME REACTION OF ZIRCALOY-2 WITH DRY HYDROGEN FOLLOWED WITH WET HYDROGEN AT $662 \mathrm{~F}$ 

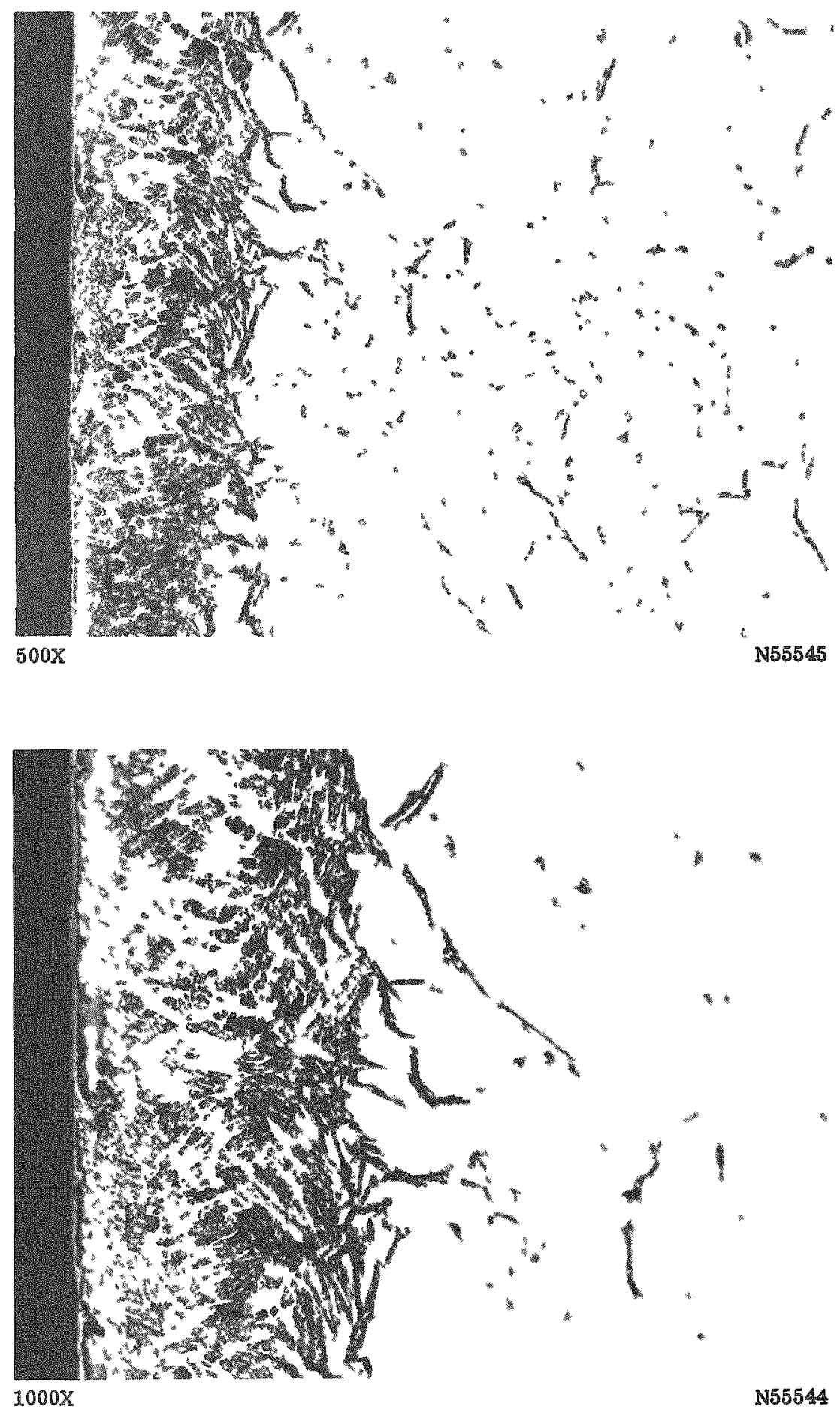

FIGURE 6. ZIRCALOY-2 REACTED WITH ORY HYDROGEN AND THEN WET HYDROGEN AT 662 F

Thun oxide film over rather thick (dark etchung) hydride layer ss shown. Etched with 1 per cent hydrofluoric acid on polsshung wheel. 


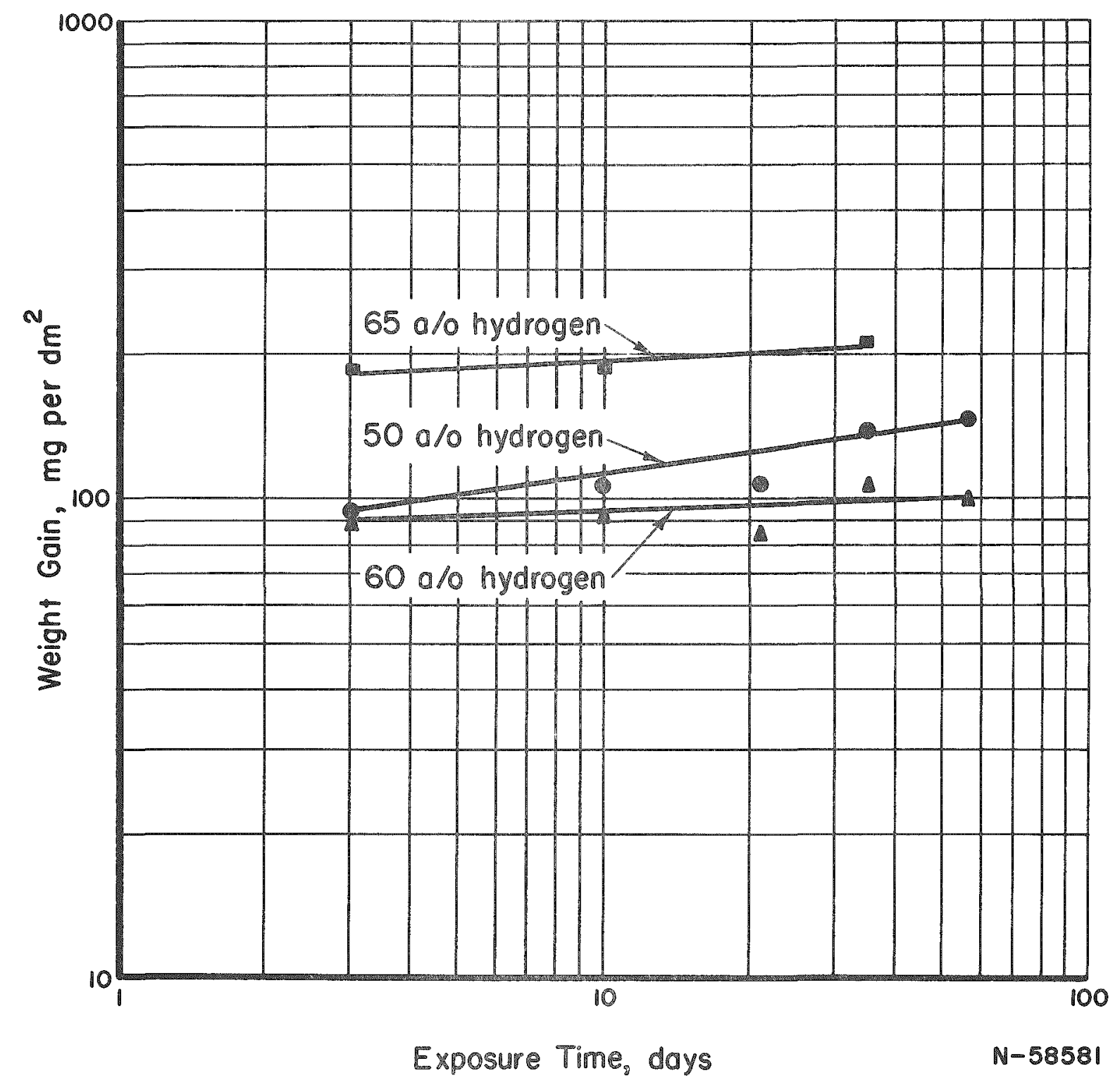

FIGURE 7. ZIRCONIUM-HYDROGEN ALLOYS EXPOSED IN STATIC 680 F WATER 
the corrosion reaction. Since small quantities of water vapor introduced into molecular hydrogen appear to stop the hydriding reaction by the formation of a continuous oxide film, the hydrogen absorbed by zirconium during corrosion is probably in the atomic or ionic state. Zirconium alloys are known to react rapidly with atomic hydrogen (e.g., cathodic charging) to form hydrides. However, in the corrosion of hydrides a protective oxide film is formed. This would indicate that the presence of hydride as a minor phase in Zircaloy-2 would not be responsible for catastrophic corrosion. Furthermore, the present study shows that the hydrogen content of the metal has little or no effect upon the amount of corrosion-produced hydrogen that enters the base metal.

In the case of metallic additions, however, there appears to be a pronounced relationship between the amount of the addition and the amount of hydrogen picked up during corrosion. While antimony, chromium, and iron decrease the hydrogen pickup, nickel increases the amount of corrosion-produced hydrogen that is picked up by the base metal. It is known that all of these elements form intermetallic compounds. These are believed to act as cathode regions, upon which hydrogen is deposited in the corrosion reaction. From the results obtained in this investigation on the amount of hydrogen absorbed by the metal with different alloy additions, it appears that the nickel compound may dissolve hydrogen and provide the diffusion path into the metal while the antimony, chromium, and iron compounds tend to release the hydrogen to the watex. Previous studies on high-purity crystal-bar zirconium, which is relatively free of compounds, have shown that hydrogen generated during coxrosion tends to form a hydride case at the metal-oxide interface. In order to fully understand the mechanism of hydrogen pickup during corrosion, it would be necessary lo determine the composition and structure of the intermetallic compounds in various alloys and to obtain hydrogen reaction-rate, corrosion rate, and solubility data for these compounds.

In addition to the studies on the reaction of hydrogen with the various compounds, the factors which affect the hydrogen permeation through the oxide film need further study. These include: (1) possible modification of the $\mathrm{ZrO}_{2}$ by the alloying elements such as chromium, iron, and nickel; (2) changes in the electrical conductivity of the oxide formed over the intermetallic compound; and (3) whether the hydrogen which permeates the oxide film is atomic, ionic, or in the form of hydroxyl ions. These and other questions need to be answered before the mechanism of hydrogen pickup by zirconium alloys during exposure to high-temperature water can be fully understood.

\section{CONCLUSTONS}

The results of this study have indicated the following conclusions with respect to hydrogen absorption in zirconium alloys during corrosion in high-temperature water.

(1) Increasing nickel content increases hydrogen absorption in zirconium alloys. As little as 0.06 w/o nickel increases hydrogen pickup by 50 per cent in sponge zirconium. In Zircaloy -2 containing up to $0.5 \mathrm{w} / \mathrm{o}$ nickel, the amount of hydrogen absorbed doubles with each fifteenfold increase in nickel content. 
(2) Additions of up through I w/o of chromium or iron reduce the hydrogen absorption in sponge zirconium, while tin has a neutral effect.

(3) Antimony additions ranging up through $1.5 \mathrm{w} / 0$ significantly lower hydrogen absorption in sponge zirconium. However, $1 \mathrm{w} / 0$ antimony in Zircaloy -2 with $0.57 \mathrm{w} / 0$ nickel alloy does not significantly retard hydrogen pickup.

(4) Two atmospheres of molecular hydrogen in the water does not affect hydrogen pickup by zirconium alloys.

(5) High hydrogen content at the surface or in the bulk alloy does not influence hydrogen absorption during corrosion.

(6) Water-vapor addition to a hydrogen atmosphere stops the hydriding reaction.

(7) The zirconium hydride itself is corrosion resistant in $680 \mathrm{~F}$ water after the initial reaction which forms an oxide film.

\section{ACKNOW LEDGMENTS}

The authors wish to express their appreciation to Mr. William Albrecht for the preparation of the hydrogen alloys and for determining reaction rates in hydrogen and hydrogen plus water vapor and to Mr. William N. Stiegelmeyer who conducted the metallographic examinations.

\section{REFERENCES}

(1) WAPD PWR PMM 1453, Minutes of the Conference on Hydrogen in Zircaloy, Bettis (February 24, 1958).

(2) Thomas, D. E., Metallurgy of Zirconium, edited by B. Lustman and F. Kerze, p 633 (1953), McGraw-Hill Book Company, Inc., New York.

(3) Schwartz, C. M., and Vaughan, D. A., "Effect of Hydrogen Pickup on Corrosion Behavior of Zirconium in Water", BMI-1120 (August 1, 1956).

WEB :DAV:ELW/ims 